\title{
Carlos V y los Reales Alcázares de Sevilla: El espacio áulico en torno al Patio de las Doncellas
}

\author{
Charles V and the Alcázar of Seville: The court space around the \\ Courtyard of the maidens \\ Candela GAITÁN SALINAS \\ Universidad de Málaga \\ ORCID: https://orcid.org/0000-0002-0327-6286 / candelagaitansalinas@gmail.com \\ Sergio RAMIRO RAMÍREZ \\ Universidad Autónoma de Madrid \\ ORCID: https://orcid.org/0000-0002-4201-4780 / sergio.ramiro@uam.es \\ DOI: http://dx.doi.org/10.18002/da.v0i19.5998
}

Recibido: 1-IX-2019

Aceptado: 7-V-2020

RESUMEN: Las intervenciones arquitectónicas que los monarcas castellanos encargaron en el Alcázar de Sevilla entre 1545 y 1547 eran poco conocidas hasta ahora, debido a la pérdida de los libros de cuentas del Real Sitio correspondientes a estos años. Este artículo pretende colmar esta carencia a través de nueva documentación inédita relacionada con la gestión de las obras por parte de la Corona. Al mismo tiempo, se exponen las decisiones tomadas por Carlos V sobre los espacios a crear y el modo en el que se relacionaban entre ellos. Por último, el trabajo evidencia el pleno conocimiento de las necesidades domésticas y ceremoniales de la familia imperial que adquirieron los maestros mayores Alonso de Covarrubias y Luis de Vega.

Palabras Clave: Arquitectura; Carlos V; Felipe II; Alcázar de Sevilla; Luis de Vega; Alonso de Covarrubias.

ABSTRACT: Until now the architectural interventions commissioned by the Spanish Monarchy at the Alcázar of Seville between 1545 and 1547 have been largely unknown. This lack of scholarship was mainly due to the loss of payment logs corresponding to those years. Thus, the aim of this paper is to fill that gap by presenting new primary documents, published here for the first time, related to the Crown's management of the commission. At the same time, the paper analyses the decisions made by the Emperor Charles V concerning the new rooms to be created and how they should interrelate. Lastly, the study evinces the knowledge that the main architects of the Monarchy, Alonso de Covarrubias and Luis de Vega, acquired regarding the domestic and ceremonial requirements of the Imperial Family.

Keywords: Architecture; Charles V; Philip II; Alcázar of Seville; Luis de Vega; Alonso de Covarrubias.

\section{INTRODUCCIÓN}

El palacio de Pedro I en el interior de los Reales Alcázares de Sevilla (Fig. 1) fue con- siderado desde su construcción entre 1356 y 1366 como "Alcázar nuevo", en contraste con las estructuras anteriores alfonsíes, o "Palacio Gótico", situadas al este de esta 


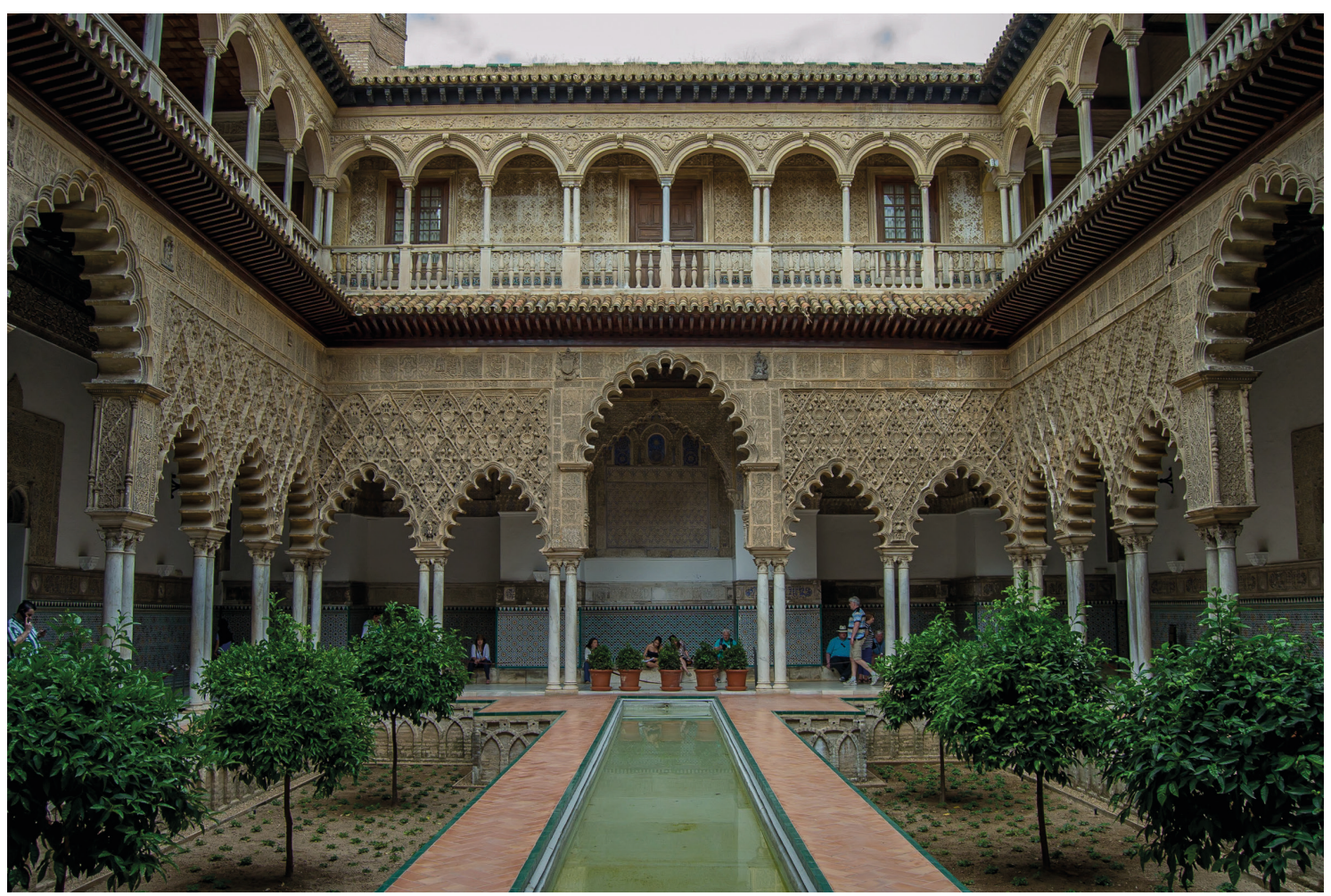

- Fig. 1: Patio de las Doncellas en el interior del Palacio de Pedro I. Siglos XIV-XVI. Sevilla, Reales Alcázares. Imagen: Alberto Bravo.

nueva zona residencial y representativa ${ }^{1}$. La muerte de Pedro I y el cambio de dinastía propiciado por su hermanastro Enrique II conllevaron un progresivo alejamiento de la Corte y el desinterés de los reyes Trastámara por el palacio sevillano, hasta que la residencia volvió a ser habitada intermitentemente con la vuelta de los Reyes Católicos a la ciudad durante la reactivación de las campañas contra el reino nazarí de Granada en el último cuarto del siglo XV.

Más de un siglo de abandono había dejado obsoleta la residencia del siglo XIV, por lo que a comienzos del Quinientos se reactivaron las intervenciones regias en torno a los patios de las Muñecas y el principal de las Doncellas, con el objetivo de adecuar sus espacios a los nuevos usos y a la comodidad requerida por los reyes Isabel y Fernando. La

\footnotetext{
${ }^{1}$ Antonio Almagro, “Los palacios de Pedro I. La arquitectura al servicio del poder", Anales de Historia del Arte, no 2 (2013), 39. Véase también Rafael Cómez, El Alcázar del rey don Pedro (Sevilla: Diputación Provincial de Sevilla).
}

reina católica concentró sus esfuerzos en una serie de estancias para su residencia en la segunda planta del ángulo noroeste que comprendía sus aposentos y el célebre oratorio privado de la reina, así como en la sala denominada "de los Reyes Católicos" en el piso bajo. Por el contrario, los cuartos del rey estaban ligados al "Palacio Gótico" de Alfonso $\mathrm{X}^{2}$ y se extendían hacia el denominado "Mirador de los Reyes Católicos"33 (Fig. 2). En el

${ }^{2}$ Rafael Domínguez Casas, Arte y etiqueta de los Reyes Católicos: artistas, residencias, jardines y bosques (Madrid: Alpuerto, 1993), 71. Sobre las obras en el Alcázar de Sevilla en tiempos de los Reyes Católicos, véase también: Alfredo J. Morales Martínez, “Los Reyes Católicos y el Alcázar de Sevilla: De la restauración a la renovación", en Los Alcázares reales: vigencia de los modelos tradicionales en la arquitectura áulica cristiana, editado por Miguel Ángel Castillo Oreja (Madrid: Fundación BBVA, 2001), 129-144.

${ }^{3}$ Sobre las intervenciones de los Reyes Católicos en este mirador: Alfredo J. Morales y Juan Miguel Serrera, “Obras en los Reales Alcázares de Sevilla en tiempo de los Reyes Católicos", Laboratorio de Arte, no 12 (1999), 6977 y Sebastián Fernández Aguilera, “Origen del Palacio 


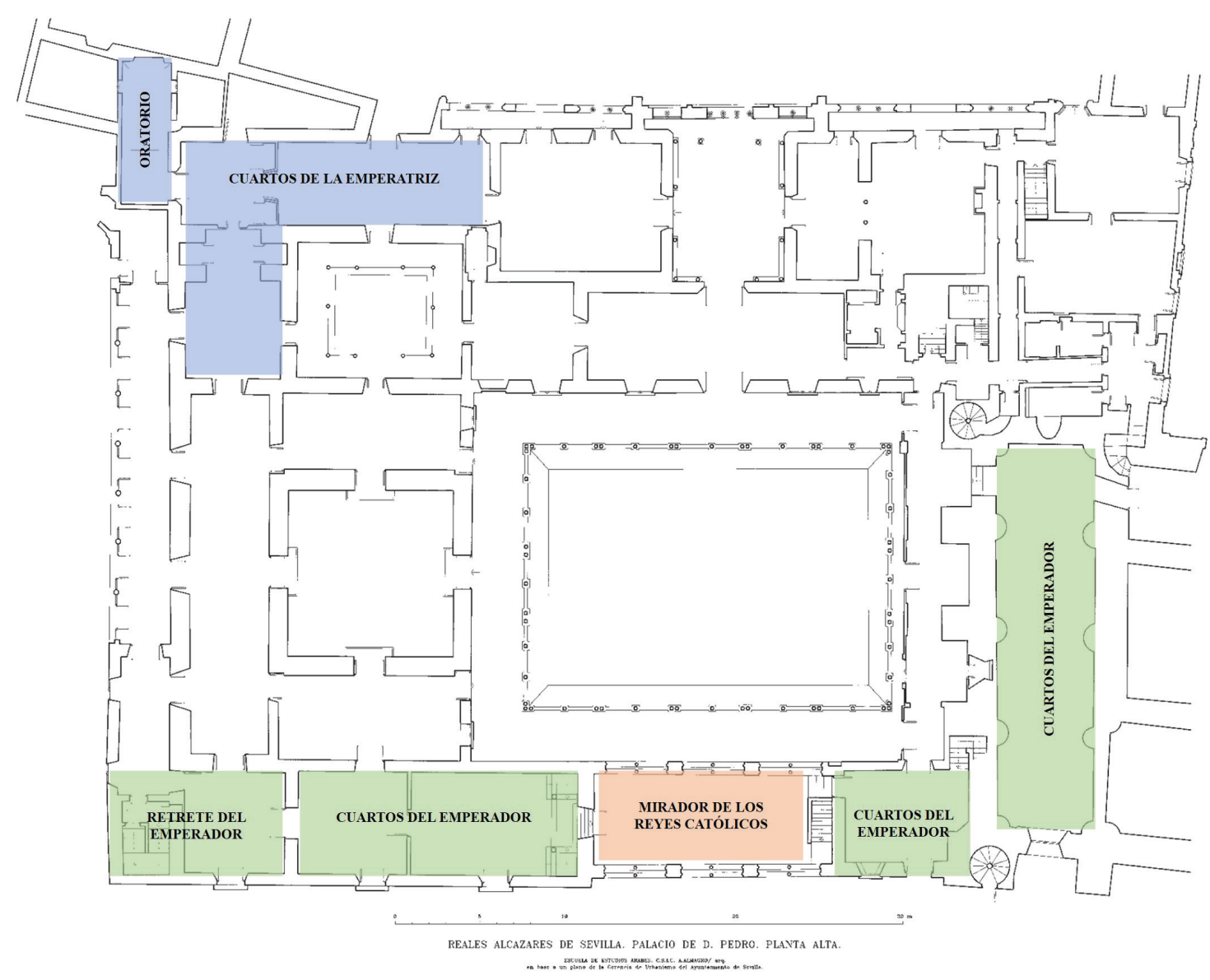

- Fig. 2: Planta alta del Palacio de Pedro I. Siglos XIV-XVI. Sevilla, Reales Alcázares. Elaboración de C. Gaitán Salinas sobre planimetría de A. Almagro Gorbea.

palacio alfonsí se situaba también la capilla real de San Clemente, creada en el siglo XIII y que probablemente era utilizada también como oratorio del rey $y^{4}$.

En 1526, el emperador contrajo matrimonio con Isabel de Portugal en la cuadra de la Media Naranja, actual Salón de Embajadores. Al igual que lo sucedido en la Alhambra ese mismo año, Carlos V e Isabel de Portugal comprobaron que la arquitectura no se adecuaba a las nuevas costumbres domésticas y a la etiqueta cortesana de la dinastía Habsburgo que, entre otras cuestiones, prescribía la completa separación de los cuartos del rey y de la reina. Además, constataron

de Pedro I en el Alcázar de Sevilla: el mirador hoy llamado de los Reyes Católicos", Archivo Español de Arte, vol. 88, no 352 (2015), 338-341.

${ }^{4}$ Cómez, El Alcázar..., 40 y 42. la necesidad de una capilla palatina donde pudieran acudir los miembros de la Corte, con un acceso para los monarcas desde sus aposentos, lo que propició la reestructuración del complejo áulico. De este modo, en la década siguiente comenzaron los trabajos de adaptación de los viejos palacios nazaríes granadinos, al igual que sucedió con las ampliaciones de los alcázares de Toledo y Madrid, o la residencia de Francisco de los Cobos en Valladolid convertida en alojamiento de la familia real en sus visitas a la ciudad pinciana ${ }^{5}$.

\footnotetext{
${ }^{5}$ La bibliografía sobre este proceso es muy abundante. Sobre el inicio de este programa de reformas, véase María José Redondo Cantera, "La arquitectura de Carlos V y la intervención de Isabel de Portugal: palacios y fortalezas", en Carlos V y las artes: Promoción artística y familia imperial, editado por María José Redondo Cantera y Miguel Ángel Zalama Rodríguez (Valla-
} 
En Sevilla, el proceso de transformación del concepto residencial del edificio afectó también a la altura del palacio y a su fisonomía. Asimismo, se introdujeron elementos formales de carácter italianizante como los artesonados de madera, las yeserías con motivos de grutescos en el piso superior o las columnas de mármol genovesas. Además, la inclusión de los emblemas del emperador en las galerías del patio lo dotaron con las señales visuales de su propiedad regia.

Sin embargo, las actuaciones no se sucedieron fruto de un único impulso. La intrincada e ineficiente gestión de las decisiones, complicada por la falta de delimitación competencial tanto en la Corte carolina ${ }^{6}$ como en la administración del Real Sitio sevillano, dilataron durante años las obras e impidieron la finalización de proyectos ambiciosos, tales como la construcción de una capilla palatina que aquí damos a conocer. No obstante, el diálogo sobre diversas ideas arquitectónicas establecido entre los encargados de las obras en Sevilla con el emperador Carlos V y su hijo, el príncipe Felipe, justifica por sí mismo un estudio que pondere justamente las exigencias de los monarcas, así como el papel de intermediarios que jugaron los maestros mayores de obras reales Alonso de Covarrubias y, sobre todo, Luis de Vega, con la colaboración de su sobrino Gaspar. Por otro lado, el estudio de estos documentos inéditos nos permite completar un período de la vida del complejo palaciego entre 1545 y 1547, hasta el momento, poco conocido por la desaparición de sus libros de fábrica? ${ }^{7}$.

dolid: Junta de Castilla y León/Universidad de Valladolid, 2000) 67-106. Para el palacio de Francisco de los Cobos y María de Mendoza en Valladolid, véase Javier Pérez Gil, El Palacio Real de Valladolid: sede de la Corte de Felipe III (1601-1606) (Valladolid: Universidad de Valladolid, 2006) 53-56.

${ }^{6}$ La recién creada Junta de Obras y Bosques (1545) se encargaría de la gestión de manera más eficaz en el reinado posterior. Sobre su historia, véase: Francisco Javier Díaz González, La Real Junta de Obras y Bosques en la época de los Austrias (Madrid: Dyckinson, 2002).

${ }^{7}$ A partir del año 1545 las series documentales están incompletas, como se reconoce en Ana Marín Fidalgo,

\section{LA GESTIÓN DEL REAL ALCÁZAR DE SEVILLA: LOS SERVIDORES REA- LES}

La documentación aquí analizada demuestra que fueron muchas las personas con participación en los proyectos de esta centuria. De hecho, entre los tres Reales Sitios castellanos que constituyen el eje Madrid-Toledo-Sevilla, este último fue el que gozó de una mayor autonomía administrativa y una organización más compleja heredada de la gestión de los monarcas precedentes.

Como es común a la mayoría de residencias fortificadas, el Alcázar de Sevilla contaba con un alcaide, que durante las primeras dos décadas del reinado de Carlos V residió en el complejo palatino asistido por un teniente, pero sin delegar su función. El cargo recayó en Jorge de Portugal y Melo, I conde de Gelves ${ }^{8}$, desde 1503 hasta su fallecimiento en septiembre de $1543^{9}$. A pesar de que nuestro análisis se centra en los años inmediatamente posteriores a su deceso, su nombre aparecerá constantemente en las comunicaciones sobre las obras, puesto que había controlado la suerte de los Alcázares durante los años precedentes.

Desde marzo de 1545, las tareas del cargo fueron asumidas de forma interina por Antonio de Cárdenas ${ }^{10}$, hasta que el emperador proveyó su nombramiento definitivo como teniente de alcaide en 1546. Cárdenas

El Alcázar de Sevilla bajo los Austrias, vol. I. (Sevilla: Ediciones Guadalquivir, 1990), 154.

${ }^{8}$ El conde de Gelves heredó el cargo de su padre Álvaro de Portugal. Su nombramiento data del 7 de octubre de 1503: Juan Gil, El exilio portugués en Sevilla: De los Braganza a los Magallanes (Sevilla: Fundación Cajasol, 2009), 34 y 69.

9 Tras el fallecimiento del conde de Gelves, el cargo quedó vacante hasta 1552 cuando el emperador, a instancias del príncipe Felipe, nombró al frente de la administración y mantenimiento del Real Sitio a Pedro de Guzmán, I conde de Olivares: Sobre esta figura, véase Ana Gloria Márquez Redondo, Los alcaides del Alcázar de Sevilla (Sevilla: Patronato del Real Alcázar, 2010).

${ }^{10}$ Archivo General de Simancas (AGS), Estado, leg. 65, docs. 238 y 239. 
había ocupado esa posición durante la administración del conde de Gelves y, tras la muerte de este, intentó modificar la política arquitectónica más conservadora de la etapa anterior. También quiso hacer lo propio con las decisiones tomadas por el emperador y el príncipe Felipe, para lo cual contó con la connivencia de los maestros mayores del Alcázar ${ }^{11}$, en especial el de albañilería Juan Fernández (†1572), autor del memorial transcrito en el apéndice, y del maestro de carpintería Juan de Simancas, propuesto para su puesto por el propio Cárdenas al príncipe Felipe $^{12}$. El teniente de alcaide consiguió también trasladar su voz a la Corte mediante la apelación continua a Francisco de los Cobos y Molina (ca. 1477-1547), consejero de Estado, secretario del príncipe y contador mayor de Castilla desde 1543, quien en la quinta década del siglo XVI se mostrará como el enlace privilegiado entre las obras sevillanas, el emperador y el heredero de la Corona.

Por último, en una posición de difícil definición se encontraron los maestros mayores de obras reales Alonso Covarrubias y Luis de Vega, oficialmente en el cargo desde 1537. A pesar de que Covarrubias fue el designado para "entender" en los trabajos de Sevilla, en 1545 Vega tomó un protagonismo creciente en detrimento de su colega ${ }^{13}$. La apuesta por Vega se confirma en la documentación que a continuación se analiza y puede tener relación con la pérdida de confianza en Covarrubias por su actuación en el Alcázar de Toledo durante estos años ${ }^{14}$. Sus

${ }^{11}$ Desde tiempos de los Reyes Católicos coexistieron tres maestros mayores según su especialidad en las técnicas necesarias para el mantenimiento de las estructuras bajomedievales: albañilería, carpintería y pintura: Domínguez Casas, Arte..., 61

${ }^{12}$ AGS, Estado, leg. 74, doc. 21.

${ }^{13}$ Eva Guerrero de Llanos, “El uso de la arquitectura como reafirmación política: la Maestría Mayor de Obras Reales en el siglo XVI y Luis de Vega", en Los Lugares del Arte: identidad y representación, vol. I, editado por Sofía Diéguez Patao (Barcelona: Laertes, 2014), 144.

${ }^{14}$ El 27 de marzo de 1544, Covarrubias ya estaba suspendido de empleo y sueldo. Una situación que labores principales consistieron en el reconocimiento de estructuras, el planeamiento de proyectos, la elección de materiales y, en definitiva, la transmisión y verificación de las órdenes de los monarcas a pie de obra; una labor que les obligó a trasladarse continuamente entre Valladolid, Madrid y Sevi1la. Sin embargo, como tendremos ocasión de comprobar, sus pareceres no estuvieron exentos de respuesta por parte de la administración del Real Sitio sevillano.

\section{PRIMERAS NOTICIAS SOBRE EL} PROYECTO

La primera noticia sobre los trabajos planteados nos informa de que Covarrubias había reconocido en 1541 o 1542 la zona donde debía ejecutarse la intervención, acompañado de una nueva traza y órdenes directas de Carlos V, probablemente dictadas durante una breve estancia en Castilla iniciada en el invierno de 1541. Según se desprende de las palabras de Cárdenas en carta a Cobos de agosto de 1545, el proyecto, consistente en la construcción en altura sobre el antiguo palacio de Pedro I y unos nuevos edificios anexos en un terreno previamente cercado, había contado con el acuerdo del arquitecto:

“[...] quando aquí vino Covarrubias habra tres o cuatro años le parecio lo mismo. Toda esta traça va conforme a los edificios viejos que dexo el rey don Pedro hechos, son muy extremadas paredes y puedese fundar sobre ellas cualquier hedificio tanbien se podra labrar lo que a Su Magestad le pareciere en el sitio que se manda cercar"15.

Durante su visita, Covarrubias diseñó un proyecto propio contenido en unos planos que fueron olvidados hasta 1545, cuando aparecen de nuevo en la documen-

puede extenderse hasta junio de 1545, cuando se reunió en Toledo una junta compuesta por Enrique Persoens, Luis de Vega, el capitán Solís y Luis Pizano, a la que se unió el propio Covarrubias, para desbloquear la parálisis de las obras: Sergio Ramiro Ramírez, Patronazgo y usos artísticos en la corte de Carlos V: Francisco de los Cobos y Molina (tesis doctoral, Madrid, 2018), 425-426.

${ }^{15}$ AGS, Estado, leg. 74, doc. 181. 
tación por la reactivación de los planes de años atrás. Mientras tanto, el abandono secular de las estructuras y las inclemencias del tiempo habían obligado a realizar ciertas actuaciones insoslayables tras el lluvioso invierno de 1544/1545 -temporal que provocó inundaciones en las Reales Atarazanas y en el Palacio Gótico- a los que se hubo de dar una respuesta provisional hasta conocer las órdenes del emperador. Su resolución fue iniciar las reparaciones más apremiantes ${ }^{16}$ y aprovechar la ocasión para acometer las obras suspendidas años antes, porque Francisco de los Cobos escribió al monarca el 25 de marzo de 1545 anunciando que se habían reclamado las trazas a Covarrubias y se había solicitado el estado de las cuentas al teniente de alcalde. Por tanto, dos actuaciones de diferente calado estaban previstas: las habituales reparaciones de urgencia y el proyecto para el que se había enviado a Covarrubias del que resultaron unos planos e, imaginamos, también un memorial.

Gracias a un nuevo mensaje de Cobos a Carlos V que data del 24 de mayo, sabemos que Covarrubias había negado poseer la documentación afirmando que ésta había quedado en la cámara del emperador custodiada por un servidor de nombre Adrián. Sin embargo, añadió un matiz interesante porque reconoce que con esos documentos "se vera lo que scrivio el marques de Cortes sobre el aposento que se havia de hazer", es decir, además del maestro mayor de obras reales, en la reestructuración de los nuevos cuartos había intervenido Pedro de Navarra y de la Cueva, asistente de Sevilla, probablemente presentando informes sobre el estado del palacio ${ }^{17}$.

${ }^{16}$ El 25 de marzo de 1545, Francisco de los Cobos escribió a Carlos V en estos términos: "se hiziese asi en los alcazares como en las atarazanas y en la casa del palacio del rey los reparos que fuesen necesarios y no se pusiesen escusas y que no haziendose luego serian despues mas costosos y no se les mando que hiziesen otras obras porque no se sabia lo que V. Magestad havia ordenado sobrello": AGS, Estado, leg. 69, doc. 82.

${ }^{17}$ AGS, Estado, leg. 69, doc. 109.
Un memorial enviado por el príncipe Felipe a Cárdenas, tras su nombramiento provisional como teniente de alcaide el 10 de marzo de 1545, trasluce su preocupación por la lentitud en la toma de decisiones, ya que ordenó algunos reparos urgentes referidos principalmente a cubiertas y estructuras que debían protegerse de la climatología adversa, llegando a decretar que no cesase la obra necesaria para reparar todos los tejados y azoteas de los Alcázares y las Atarazanas "de las galeras y de los caballeros"18. Junto a la finalización de obras puestas en marcha con anterioridad, como la reforma de la noria comenzada en la Huerta de la Alcoba y no completada hasta el momento, el príncipe Felipe hizo especial hincapié en la consolidación de las estructuras que formaban parte de los antiguos astilleros, como el tejado de la capilla de las Atarazanas de los Caballeros y el balcón que sobresalía en su exterior. Además, el príncipe demuestra en el documento el conocimiento exhaustivo que poseía del estado del complejo palatino y de las Atarazanas gracias a los informes de sus administradores. Por ejemplo, ordenó renovar tres o cuatro vigas que se encontraban rotas en la caballeriza junto al acceso de palacio para evitar el derrumbe de las habitaciones y de la azotea sobre ella, al tiempo que recordó los cuartos reales sobre la fachada del Patio del Crucero o las habitaciones junto a la denominada "cuadra de San Jorge" $^{\prime \prime}$ anticipándose a su posible mal estado y ordenando que fuesen intervenidos ${ }^{19}$. Proba-

\footnotetext{
${ }^{18}$ Desde mediados del siglo XV, las Reales Atarazanas alfonsinas perdieron progresivamente su dedicación a la construcción de barcos y comienza el empleo de sus distintas naves a otras tareas como almacenaje, uso comercial y viviendas, por lo que la Corona alquilará parte de su espacio y también cederá algunas naves al concejo de la ciudad. Sobre su historia, véase Matilde Fernández Rojas, Las Reales Atarazanas de Sevilla (Sevilla: Diputación de Sevilla, 2013) y Pablo Emilio Pérez-Mallaína, Las Atarazanas de Sevilla: Ocho siglos de historia del arsenal del Guadalquivir (Sevilla: Diputación de Sevilla, 2019).

${ }^{19}$ AGS, Estado, leg. 65, doc. 237. El Cuarto de San Jorge estaba constituido por planta alta y baja, además de un patio con cuatro galerías de madera, formando
} 
blemente había surtido efecto el aviso sobre la situación preocupante del denominado "Palacio del Rey" que el marqués de Cortes le había enviado a 25 de enero de $1545^{20}$.

No obstante, a pesar de estas disposiciones generales, el heredero no quiso tomar decisiones de calado hasta que su padre nombrase un teniente de alcalde que finalizase el período de interinidad en el que se encontraba Cárdenas. Esto explica por qué, a pesar de acometer la reconstrucción completa de la cubierta-chapitel de la "cuadra de San Jorge" sustituyendo los azulejos por tejas, pidiese expresamente que no se instalase "el maderamiento rico", es decir, una armadura que se había preparado para su interior, "hasta que Su Magestad provea de la dicha tenencia a quien fuere servido" ${ }^{21}$.

De este modo, tras haber bosquejado la situación en la que se encontraban los edificios del complejo palatino sevillano, es preciso centrarse en los espacios que conformaron los cuartos del rey y los de la reina en torno al Patio de las Doncellas, pues en ellos Luis de Vega desplegó su habilidad para el maridaje entre las estructuras antiguas y las nuevas, así como su capacidad para plegarse a los deseos de la monarquía, ambas las causas principales de su éxito como arquitecto de la realeza.

\section{LAS OBRAS EN LOS CUARTOS DEL REY}

Durante estos meses convulsos, en los que ni siquiera era posible recuperar la documentación generada en el proyecto, inició la participación de Luis de Vega en Sevilla. El arquitecto hizo acto de presencia por primera vez en los Alcázares por una orden de Carlos V fechada a 16 de agosto de 1545 en carta desde Colonia, que incluía instruc-

parte del Palacio Gótico: Marín Fidalgo, El Alcázar de Sevilla..., 151-152.

${ }^{20}$ AGS, Estado, leg. 72, doc. 265.

${ }^{21}$ AGS, Estado, leg. 65, doc. 239. ciones dictadas por el propio emperador ${ }^{22}$. Las trazas de Covarrubias antes aludidas y los informes del marqués de Cortes desde mediados del siglo XVI llegaron a poder de Carlos V, porque en la misma carta el emperador había escrito: "Asimismo embiamos la traza de las obras del alcazar de Sevilla que teniamos aca para que conforme a ella se vaya labrando" y el 24 de septiembre volvió a remitirlas a España añadiendo que le habían sido entregadas por su hijo Felipe, ya que apuntó: "En lo que toca a las obras de Sevilla, havemos visto las traças que nos embiaste de lo alto y baxo que hizo Covarrubias y otras del oficial que tiene cargo de las del alcaçar [...] puedese mirar y comunicar por Luys de Vega y el otro oficial" ${ }^{23}$.

De esta forma describió la caótica situación Francisco de los Cobos a Carlos V en una carta tres días más tarde, en la que se añadió información sobre una nueva planimetría y proyecto de las obras:

"Sin esperar a que V. Mt vea la nueva traça que se le embio de lo de Sevilla se ha mandado a Luis de Vega que luego vaya Sevilla con las traças que $\mathrm{V}$. Mt. ha embiado de aquella casa y asimismo se ha scripto al marques de Cortes la voluntad e intencion de V. Mt. en las obras, por que entretanto que se entiende en labrar las piezas del aposento que scrivio al dicho marques y se adereçan los materiales, podra venir la respuesta de lo que se a scrito a V. Mt."24.

En relación a las piezas de aposento mencionadas, sabemos que, en búsqueda de la comodidad que habría echado en falta durante su estancia de 1526 y con el fin de aumentar la extensión de los cuartos del rey con un gasto mínimo, el emperador había decidido eliminar la capilla de la planta baja, la actual "Sala del Techo de Carlos V"25,

${ }^{22}$ AGS, Estado, leg. 70, doc. 9.

${ }^{23}$ AGS, Estado, leg. 53, doc. 2, carta de Carlos V al príncipe Felipe con una nota para el comendador mayor de León.

\footnotetext{
${ }^{24}$ AGS, Estado, leg. 69, doc. 134.

${ }^{25}$ Juan Carlos Pérez Ferrer y Sebastián Fernández
} 
junto a otras cuatro estancias que el César denominaba los entresuelos "donde posaba Laxao" ${ }^{26}$ que se extendían hasta el ángulo suroeste del patio. Así se deduce de una misiva escrita por Cárdenas para Cobos, en la que le explicaba que el corredor sobre el Jardín del Príncipe tras la Sala de la Media Naranja "junta por el un hastial con las piezas que agora se hacen sobre los entresuelos de Laxao y por el otro hastial se junta con el aposento donde posaba la emperatriz Nuestra Señora" ${ }^{27}$.

En la zona sur se encontraban las mejores estancias para la comodidad del rey. Estas ofrecían unas vistas privilegiadas de la Huerta de la Alcoba ${ }^{28}$-posteriormente transformada en el Jardín de las Flores y Jardín de la Galera ${ }^{29}$ - y su famoso cenador que

Aguilera, "La restauración del artesonado de la Sala del Techo de Carlos V del palacio mudéjar del Real Alcázar de Sevilla", Apuntes del Alcázar de Sevilla, no 11 (2010), 340-341 y Fernández Aguilera, “Origen del Palacio de Pedro I...", 338-341.

${ }^{26}$ AGS, Estado, leg. 70, doc. 9, carta de Carlos V a Francisco de los Cobos a 16 de agosto de 1545 y AGS, Estado, leg. 72, doc. 262, carta de Antonio de Cárdenas a Francisco de los Cobos. "Laxao" es la corrupción del título de Charles de Poupet, señor de La Chaulx (ca.14601530). La Chaulx fue uno de los preceptores del emperador, así como su chambelán, primer sumiller de corps y uno de los diplomáticos encargados del acuerdo matrimonial entre Carlos V e Isabel de Avis: Carlos Javier de Carlos Morales, La corte de Carlos V: Vol. 2, Tomo 3: Los consejos y los consejeros de Carlos $V$. Coordinado por José Martínez Millán (Madrid: Sociedad Estatal para la Conmemoración de los Centenarios de Felipe II y Carlos V, 2000), 351-352.

${ }^{27}$ AGS, Estado, leg. 72, doc. 263, carta de Antonio de Cárdenas a Francisco de los Cobos a 17 de diciembre de 1545 .

${ }^{28}$ El 23 de agosto de 1545, el teniente de alcaide Antonio de Cárdenas escribió a Francisco de los Cobos que este era el mejor aposento para el monarca debido precisamente a las vistas que ofrecía: “Su Magestad provea que se labre porque por buenos aposentos que en la casa se hagan ninguno será mas apazible que este por ser sobre la Huerta del Alcoba e la vista al canpo e al maestro día y aunque otros se hagan mas anchos e mas cunplidos por lo que tengo dicho creo Su Magestad posara siempre en este": AGS, Estado, leg. 74, doc. 181.

${ }^{29}$ Ana Marín Fidalgo, “Los jardines del Alcázar de contemporáneamente se estaba reformando. Una vez realizado el cerramiento del "Mirador de los Reyes Católicos" en 1542 y retirado una especie de toldo llamado quitasol que protegía las habitaciones de los rayos solares $^{30}$, Carlos V aprobó alzar las tapias y construir algunas salas en planta alta siguiendo una nueva propuesta de ordenación contigua para la que Covarrubias podría perfectamente trazar la composición ${ }^{31}$. Por una minuta de carta de Carlos $\mathrm{V}$ a Covarrubias, seguramente anterior a la llegada de Vega a Sevilla en septiembre de $1545^{32}$, sabemos que debían elevar la fábrica del cuarto real reforzando las estructuras inferiores para construir las nuevas estancias en las que volverían a utilizar la misma cubierta, excepto para una de ellas que sería nueva:

"Sobre lo de que en vida del conde de Gelves se abajó el quitasol que estaba en el cuarto real que sale sobre la Huerta de la Alcoba donde se hizo una sala al peso de los corredores la qual dice que no tiene más que un hastial y que están cuatro entresuelos donde posaba Laxao y que daria mucho ser aquella casa doblarlos el paso ella misma sala en lo qual haurá poco que las mas de alzar las paredes cinco o seis tapias y tornar a poner las armaduras que hay excepto para la una pieza que se ha de hacer nueva en todo en lo cual se podrá gastar poco y quisiera saber si eso está metido en la traza, no hay

Sevilla durante los siglos XVI y XVII. Intervenciones y ordenación del conjunto en el Quinientos", en Los jardines del Real Alcázar de Sevilla. Historia y Arquitectura desde el Medievo islámico al siglo XX. Editado por Ana Marín Fidalgo y Carlos Plaza (Sevilla: Patronato del Real Alcázar y Casa Consistorial, 2015), 116.

${ }^{30}$ Sobre las primeras intervenciones en planta alta, incluyendo el "Dormitorio de D. Pedro" entre 1540 y 1543, véase Marín Fidalgo, El Alcázar..., 161-164.

${ }^{31}$ AGS, Estado, leg. 70, doc. 9 y AGS, Estado, leg. 72, doc. 136, carta del marqués de Cortes a Carlos V.

32 El 6 de julio de ese año, Cárdenas trasladó a Carlos V su impaciencia en la espera de la llegada de Covarrubias con las trazas, algo que creemos no se produjo: AGS, Estado, leg. 72, doc. 128. 
nada que decir, pero que si es nuevo que lo especifique para que él lo entienda mejor" ${ }^{\prime 3}$.

Esta área de palacio estaba destinada al recreo del emperador quien, desde sus cuartos principales emplazados en el Palacio Gótico -junto al Jardín del Crucero- tendría también acceso a través de una escalera y un pasillo a las estancias que se estaban habilitando en el Patio de las Doncellas, incluidas las destinadas a los aposentos de la reina como se desprende del mismo memorial de Juan Fernández incluido en el apéndice de este trabajo:

"la escalera va puesta entre el patio del crucero y el de la montería porque sirva a ambos patios y en lo alto della dexo un pasaje entre el escalera y la pared del crucero para que Su Majestad pase sin salir a corredor desde su aposento a lo alto del cuarto real y a donde posare la emperatriz. Este aposento de Su Majestad esta sobre el Crucero".

Por último, cabe añadir que, a pesar de lo escrito a Covarrubias, esta obra se llevó a cabo bajo la dirección de Vega, puesto que el emperador dejó bien claro que debía ser este último el encargado de poner en ejecución sus instrucciones: "Y porque se haga y entienda mejor agora a los principios y no se pueda errar será bien que Luis de Vega venga luego ahí y se le dé la dicha traza y vaya con ella a Sevilla y lo haga empezar a poner en execución ${ }^{34 \prime}$. Por otro lado, el 26 de abril de 1546 el príncipe Felipe escribió a Cárdenas: "Está bien lo que dezís que se labra en

${ }^{33}$ AGS, Estado, leg. 69, doc. 207, carta de Carlos V a Alonso Covarrubias y a Luis Pizaño. Estas son las que actualmente están consideradas como el Retrete del rey, el Antecomedor y el Comedor de Familia pues, efectivamente, este último tiene un enmaderamiento del siglo XVI: Marín Fidalgo, El Alcázar..., 162. Las salas colindantes con el Palacio Gótico, que no eran de nueva obra pero que se adaptan para tal fin, son el antiguo dormitorio del rey don Pedro -actual Cuarto de los Lagartos- y el citado mirador. El documento confirma la reconstrucción en la que los restauradores del Alcázar de Sevilla vienen trabajando desde hace varios años: Fernández Aguilera, “Origen del Palacio...", 338-340.

${ }^{34}$ AGS, Estado, leg. 70, doc. 9. los entresuelos donde posó Laxao conforme a lo que Su Magestad mandó y Luis de Vega dexó hordenado" ${ }^{\prime 35}$. Durante este año de 1546 se nos informa de que las obras estaban casi acabadas ${ }^{36}$ y parece que el trabajo se completó a comienzos del año 1547, porque así se le hizo saber al príncipe Felipe ${ }^{37}$.

LOS CUARTOS DE LA REINA: EL PROYECTO DE UNA CAPILLA PALATINA

En cuanto a los nuevos aposentos destinados a los cuartos reales femeninos, estos aprovecharían la ubicación de los que fueron los de la reina Isabel la Católica, quedando así ubicados en la zona noroeste del Patio de las Doncellas, en torno al Patio de las Muñecas. Esta intervención buscaba modernizar los aposentos de la futura reina, pues la emperatriz Isabel había fallecido en $1539 \mathrm{y}$, aunque Carlos V no había contraído matrimonio de nuevo, no se sabía si volvería a hacerlo. Asimismo, se proponía encontrar acomodo al resto de las damas de su casa. Por tanto, es posible imaginar su envergadura, ya que además se trataba de la empresa arquitectónica que el emperador consideraba "como la obra principal".

Para este encargo confió de nuevo en Vega, de quien requirió una solución satisfactoria a los problemas que surgirían en la adaptación de las estructuras antiguas a las nuevas funciones. El proyecto planteaba la construcción de una capilla palatina a emplazar junto a los cuartos llamados "de la emperatriz" colindante con la Casa de la Contratación (Fig. 3). La necesidad surgió, probablemente, por la pérdida de la antigua entre los años 1541 y 1543, transformada en el conocido como Salón del Techo de Carlos

\footnotetext{
${ }^{35}$ AGS, Estado, leg. 74, doc. 21.

${ }^{36}$ AGS, Estado, leg. 74, doc. 185, carta de Antonio de Cárdenas al príncipe Felipe de 20 de septiembre de 1546.

${ }^{37}$ AGS, Estado, leg. 74, s/f, minuta de carta del príncipe Felipe a Antonio de Cárdenas a ¿13 de febrero? de 1547.
} 


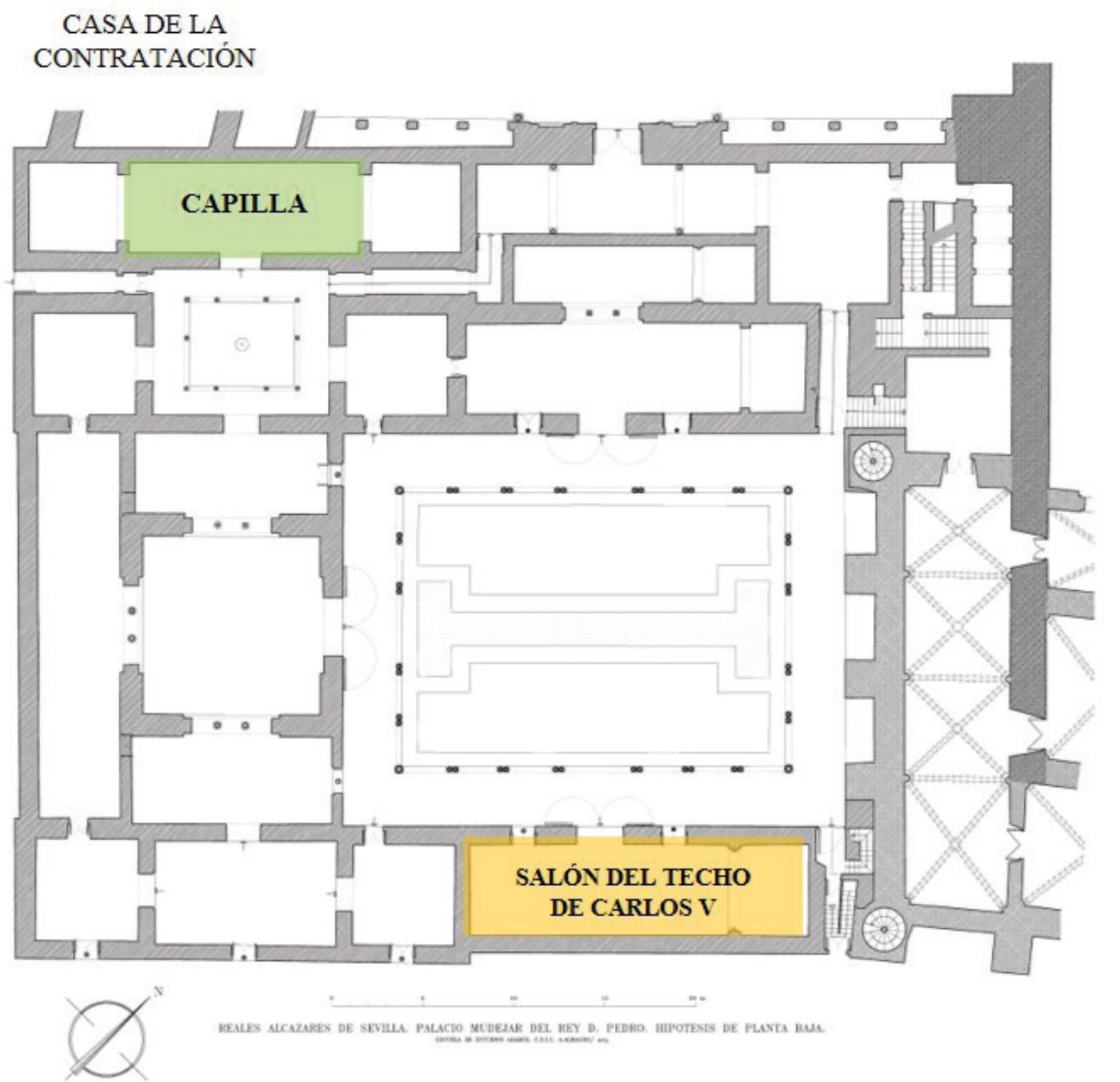

- Fig. 3: Planta baja del Palacio de Pedro I. Siglos XIV-XVI. Sevilla, Reales Alcázares. Elaboración de C. Gaitán Salinas sobre planimetría de A. Almagro Gorbea.

$\mathrm{V}^{38}$. Una cuestión de difícil encaje por el escaso espacio disponible que, a la llegada de los Vega a la ciudad hispalense, donde trabajaron durante algunos meses ${ }^{39}$, originó un diálogo con las propuestas del personal del Alcázar. Para recomponer este intercambio

${ }^{38}$ Marín Fidalgo, El Alcázar..., 166.

39 También intentaron conseguir otros encargos como el del Hospital de la Sangre en este mismo año: Alfonso Jiménez Martín, “Cronología documentada del contexto, antecedentes, construcción y uso del hospital de las Cinco Llagas, o de la Sangre, sede del Parlamento de Andalucía", en El edificio sede del Parlamento de Andalucía. El Hospital de las Cinco Llagas (Sevilla: Parlamento de Andalucía, 2017), 218. de pareceres contamos casi exclusivamente con los mensajes enviados desde Sevilla a la Corte, pero son suficientes para intuir cuáles eran las posiciones defendidas por el emperador y su hijo.

Por unos capítulos de carta de Carlos V al príncipe Felipe fechados el 23 de octubre de 1545 en los que se comenta una propuesta llegada de Sevilla, sabemos que el monarca pretendía construir una sala grande en los cuartos femeninos, una idea que contemporáneamente se estaba aplicando en otras residencias regias como el Alcázar de Madrid. Además, a esta pieza se sumaba la capilla 
palatina, causando los consiguientes problemas de disponibilidad de espacio:

"aunque esta [traza] que agora vino del maestro de Sevilla nos paresçe bien y que estas pieças eran mayores espeçialmente la sala grande entendemos que no dexan capilla como antes estava traçado, lo qual no convernia, pero haziendose aquella, en lo demas puedese mirar y comunicar" ${ }^{\prime 4}$.

En diciembre de ese año, una serie de misivas enviadas por Antonio de Cárdenas a Francisco de los Cobos, en cuyo debate se introduce el tenor del memorial del maestro Juan Fernández que aquí presentamos, aportan nuevas pistas sobre este particular. La carta de Antonio de Cárdenas a Cobos fechada el 17 de diciembre de 1545 nos informa que Luis de Vega ha partido de la ciudad hacia la Corte y solicita que no se ejecute la idea de patio ordenada por el rey, debido a su coste y porque suponía "hazerse un muy ruin aposento y ansi lo tengo dicho al marques de Cortes tomándose o no tomándose la contratación Vuestra Señoria la haga que el patio sea grande y el escalera se ponga donde mas convenga"41. Ese mismo día, una carta de Pedro de Navarra nos aporta una nueva clave de lectura, pues el asistente valora muy positivamente las nuevas instrucciones enviadas por el rey e informa que, tras discutirlas con Gaspar de Vega "muy buen oficial" y "con el que tiene a cargo de la obra", defiende que el patio y la fachada del palacio siempre le habían parecido pequeño, pero que no se habían modificado porque Luis de Vega siempre quiso mantener la Casa de la Contratación. Navarra anunció aquí el envío de un nuevo proyecto que aprovechaba parte de la Casa de la Contratación para ampliar la sala que requería el emperador "que será mayor que la de Toledo ni la de Madrid", así como otras estancias. En la misma carta también afirmó que aún quedaría espacio disponible para que la Casa de la Contratación llevase a cabo su tarea sin sentir perjuicio ${ }^{42}$. Por tanto, desde Sevilla se intentó ofrecer resistencia a lo ordenado desde la Corte y se señaló a Cobos como el interlocutor preferente para disuadir a Carlos de su empeño. Este particular se confirma en la carta de Cárdenas a Cobos de 31 de diciembre, en las que se anuncian unas nuevas "trazas", junto a un memorial escrito por Juan Fernández que reproducimos en el apéndice ${ }^{43}$.

En este documento, Fernández detalló la disposición de algunas de las habitaciones del Cuarto Real Alto, concretamente las destinadas a la emperatriz, que formaban un conjunto formado por su alcoba, la de sus damas, la capilla y la nueva escalera. Al mismo tiempo se intentaron dar soluciones a algunos de los problemas planteados hasta el momento, como las dimensiones de las salas del piso alto.

Así, el memorial comienza aludiendo al tamaño de las habitaciones y al de la capilla: "Vista la voluntad de su Magestad por vuestra carta que el marques de Cortes me mostro por la qual dize que esta bien con mi traça por que le doy las pieças mayores que la otra traça con tanto que le de capilla". Esta se ubicaría entonces colindando con la Casa de la Contratación junto a los aposentos de la emperatriz y el oratorio, de manera que quedaría establecida en el piso inferior permitiendo que tanto la emperatriz -desde sus aposentos- como Carlos V -desde el Cuarto de Hércules o de las Cinco Cuadras- pudiesen ver la misa en el piso superior:

"Va la capilla arrimada a la pared de la casa de la Contratacion tomando parte del sitio que se cerro de nuevo el anchura y longura por la traça se vera esta capilla es junto al aposento que ha de ser de la emperatriz y junta con los oratorios para que desde el dicho aposento se pueda ver misa y su magestad desde la tribuna" .

\footnotetext{
${ }^{42}$ AGS, Estado, leg. 72, doc. 264.

${ }^{43}$ AGS, Estado, leg. 74, doc. 190.
} 


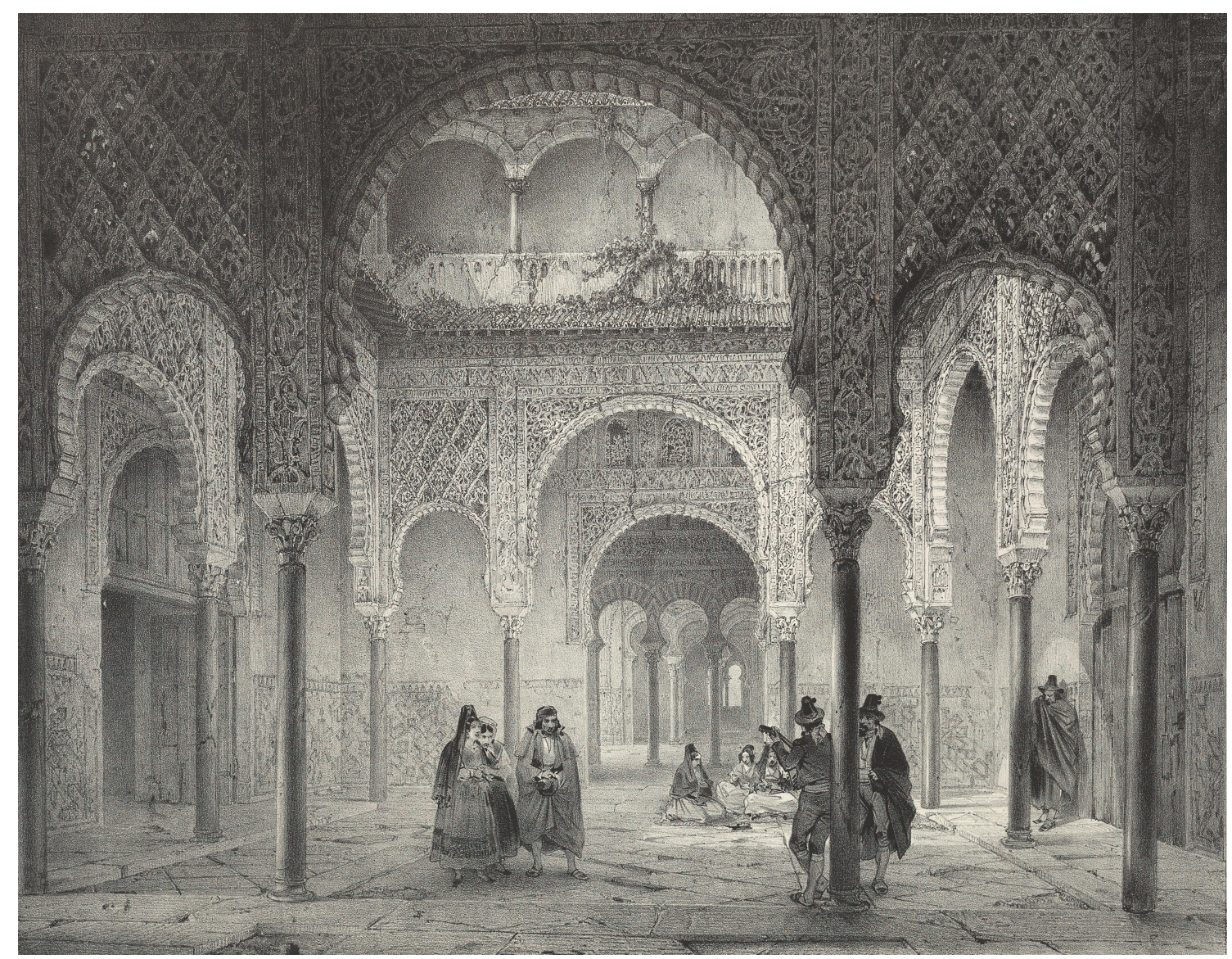

- Fig. 4: Joseph- Philibert Girault de Prangey. Monuments arabes et moresques d'Espagne contenant; souvenirs de Grenade et de l'Alhambra; mosquée de Cordue; Alcazar et Giralda de Seville. Vues générales, interieurs, détails, coupes et plans. París: Chez Veith et Hauser, 1839, ilustración 5.

También se plantea una solución muy significativa para el cuarto de las damas pues, la misma propuesta la encontramos en la carta de Cárdenas a Cobos, alegando iguales motivos para su emplazamiento en la parte noroeste del palacio: "El aposento de las damas se haze sobre la capilla [..] porque estaran las damas junto a la emperatriz y dándoles el aposento sobre la gran sala es ponerlas entre los hombres ${ }^{4{ }^{\prime \prime}}$. No obstante, Fernández añade que el cuarto tiene vistas hacia el "Canpo de Tablada" y el río, pero no impediría la entrada de luz solar al patio. Este dato nos indica que el cuarto de las damas tendría su emplazamiento en un piso superior al de la emperatriz, de lo contrario no peligraría la iluminación natural del Patio de las Muñecas, pero muy cerca de este y no

${ }^{44}$ AGS, Estado, leg. 72, doc. 262. sobre la sala grande que se había proyectado. Asimismo, la proposición de Fernández de hacer entresuelos debajo de la cámara de la emperatriz y la afirmación de Cárdenas de que colocarlas sobre la gran sala sería situarlas entre los hombres "y descender de muy alto ${ }^{45}$ " apoyan esta idea. En este sentido, nos preguntamos si durante estas intervenciones para adecuar la zona como espacio de damas no se crearía el antecedente de la galería de arcos rebajados de finales del siglo $\mathrm{XVI}^{46}$ que representa Philibert Girault de Prangey en 1837 en la segunda planta del Patio de las Muñecas, desaparecida con la intervención historicista realizada en este mismo siglo ${ }^{47}$ (Fig. 4).

\footnotetext{
${ }^{45}$ AGS, Estado, leg. 72, doc. 262.

${ }^{46}$ Marín Fidalgo, El Alcázar..., 228-229.

${ }^{47}$ María Rosario Chávez González, El Alcázar de Se-
} 


\section{OTRAS OBRAS EN EL PALACIO DE PEDRO I}

La escalera es el último de los espacios tratados en el memorial donde se propone su ubicación "entre el patio del crucero y el de la montería" para que sirva de conexión a ambos conjuntos. Asimismo, como ya se ha mencionado, se plantea dejar un pasaje entre la escalera y la pared que colinda con el patio del Crucero para que el emperador pueda realizar un recorrido privado desde el Palacio Gótico al Cuarto Real Alto y los aposentos de la emperatriz sin necesidad de salir al corredor (Fig. 3). Sin embargo, en la carta de Cárdenas a Cobos el 31 de diciembre de 1545 aparece descrita otra escalera ubicada justo en el lado opuesto del patio de la Montería: "la escalera se pone donde oy dia es el patio se le da toda la grandeza que se le puede dar sin tomar de la Contrataçion mas de lo que tengo escrito ${ }^{48}$. Estas propuestas traslucen una preocupación por dar solución al problema que ya a 17 de diciembre de 1545 parecía haberse originado debido al dilema del aumento del patio, pues Cárdenas escribió ese día a Cobos: "la escalera se ponga donde mas convenga ${ }^{49 \prime \prime}$.

Unos meses antes, en agosto de ese año, comprobamos incluso cómo Cárdenas ya expresaba inquietud generada por este asunto y barajaba la construcción de dos escaleras: una "conforme a la traça que Su Magestad enbio que es la que esta junto a la Contratación ${ }^{\prime 50}$-coincidente con el emplazamiento actual de la escalera real desde el Patio de la Montería construida a finales del siglo XVI- mientras que la otra se encontraría en el ángulo noreste del Cuarto Real aprovechando la escalera ya existente y "otra que esta perdida $[. .$.$] y sale al patio de la$

villa en el siglo XIX (Sevilla: Patronato del Real Alcázar de Sevilla, 2004), 59-60.

${ }^{48}$ AGS, Estado, leg. 72, doc. 262.

${ }^{49}$ AGS, Estado, leg. 72, doc. 263.

${ }^{50}$ AGS, Estado, leg. 74, doc. 181, carta de Antonio de Cárdenas a Francisco de los Cobos. monteria" ${ }^{\prime 21}$. Efectivamente, Cárdenas hacía mención a dos escaleras existentes en esta zona del palacio de Pedro I que servían para comunicar la planta baja con los aposentos principales de la zona alta. Almagro Gorbea dio a conocer ambas y las denominó "pública" y "privada". Estas permitían acceder al piso superior a través de dos recorridos diferentes, la "pública" desde el segundo zaguán de acceso al patio y la "privada" desde un espacio que originalmente era un patio entre el Cuarto Real y el Cuarto del Caracol. Ambas son contiguas y sus alturas convergen en un descansillo, por lo que estaba prevista su comunicación. Además, el investigador publicó también una escalera fallida cuyo arranque se encuentra cerca de las anteriores ${ }^{52}$. Con esta propuesta, el teniente de alcaide quiso aumentar la monumentalidad de la escalera para el rey, aprovechando el espacio que ocupaba la antigua, la escalera desconocida y una torre maciza que estaba junto a ellas para no perjudicar ninguna otra estancia ${ }^{53}$.

En cuanto a las cocinas, el memorial de Juan Fernández nos aporta una información valiosa que ahonda en el conocimiento sobre otro espacio planteado en estas décadas y materializado años después; ya que propone la construcción de este ámbito de servicio junto a los cuartos femeninos, como efectivamente aparece emplazado en el plano de Vermondo Resta de 1608 junto a la Casa de la Contratación, tras su construcción por el milanés en el siglo XVII (Fig. 5) ${ }^{54}$.

${ }^{51}$ AGS, Estado, leg. 74, doc. 181.

${ }^{52}$ Antonio Almagro Gorbea, "La planta alta del palacio de Pedro I en el Alcázar de Sevilla", Anuario del Departamento de Historia y Teoría del Arte, vol. 27, (2015), 79.

53 "Vera Vuestra Señoria como van dos escaleras traçadas la una conforme a la traça que Su Magestad enbio que es la que esta junto a la Contrataçion la otra es la vieja que se puede hazer una de las buenas escaleras que hubiere en el reino con desbaratar una torre maçiça y con el escalera que hoy sirve y con otra que esta perdida por manera que se hara sin dañar ninguna pieça y sale al patio de la montería": AGS, Estado, leg. 74, doc. 181.

\footnotetext{
${ }^{54}$ Por otro lado, tal y como confirma Marín Fidalgo,
} 


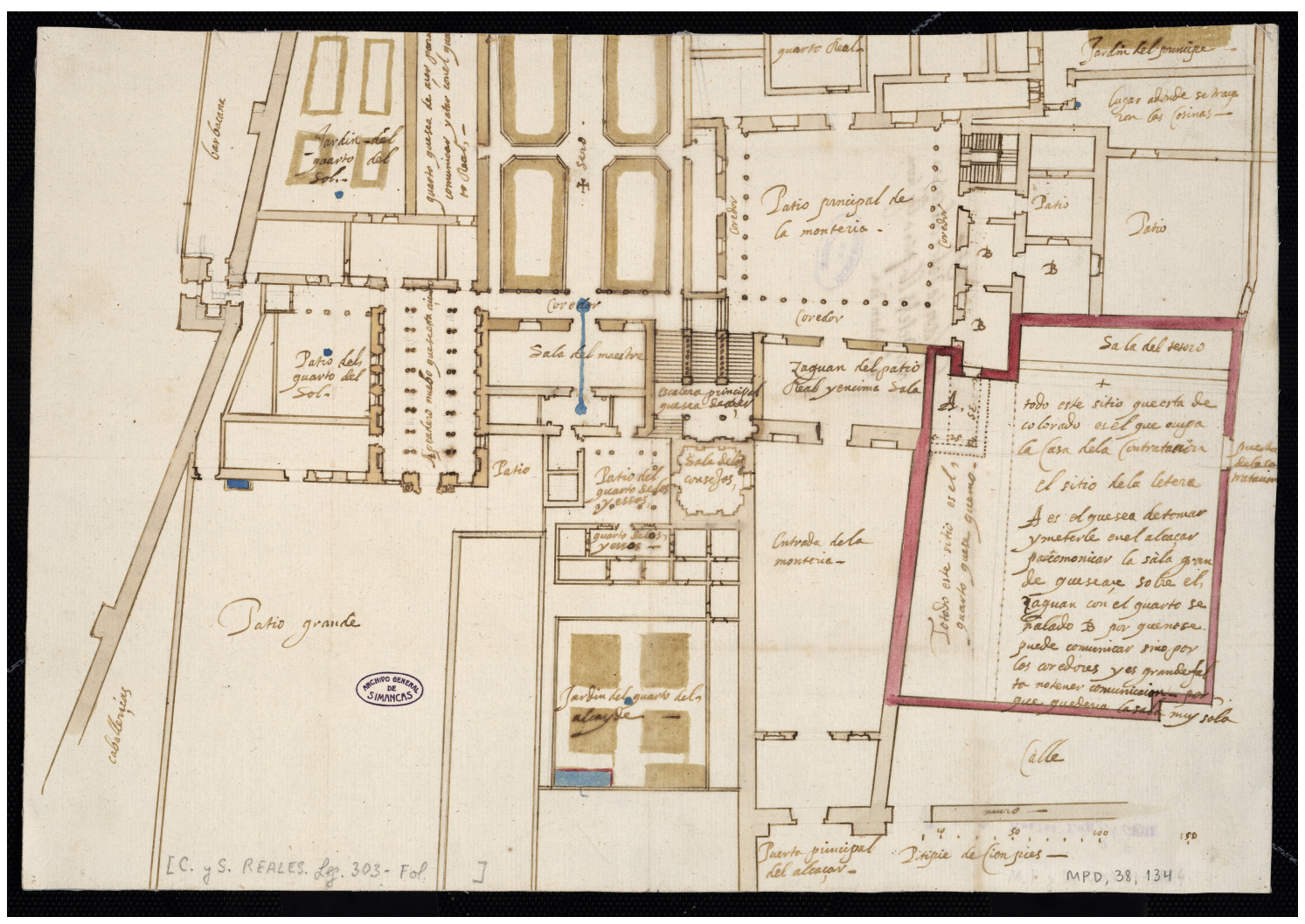

- Fig. 5: Vermondo Resta (atribuido). Planta de los Reales Alcázares de Sevilla. ca.1608. Archivo General de Simancas, Mapas, planos y dibujos, 38, 134.

La última de las modificaciones más reseñables a la que se hace referencia en estos documentos es la del pavimentado del Patio de las Doncellas. Sabemos que durante mucho tiempo el aspecto del patio-jardín fue el de un espacio enlosado con una fuente, pero su aspecto original fue muy diferente. Los trabajos realizados por Antonio Almagro Gorbea y Concepción Rodríguez Moreno en la primera década de este siglo ponen en va-

existieron otras en el Cuarto del Cidral que se deben a la iniciativa de Carlos V y que daban servicio al Palacio Gótico: Ana Marín Fidalgo, Vermondo Resta (Sevilla: Diputación de Sevilla, 1988), 52-53 y 55 y Marín Fidalgo, El Alcázar..., 147. Sobre estas últimas, es posible añadir una nueva información que explica cómo Cárdenas defendió en 1548 su construcción "porque no interfiere con la traza que el emperador debe mandar". De este modo, el teniente de alcaide solicitó al secretario Juan Vázquez de Molina, en una misiva de 13 de noviembre de 1548, que se informase de estos trabajos por Luis de Vega y permitiese hacer las nuevas cocinas "porque actualmente las que hay son las viejas que no son suficientes en caso de que la corte fuese a habitar el palacio": AGS, Estado, leg. 66, doc. 140. lor la originalidad con la que fue concebida este espacio. El patio presentaba una configuración rectangular en la que se proyectó una alberca con forma de $\mathrm{H}$ con un jardín rehundido a ambos lados estando todo el conjunto circundado por andenes que permitían el paso ${ }^{55}$ (Fig. 6). Sin embargo, esta configuración cambió tempranamente nivelando el terreno y eliminando así los jardines para dejar únicamente una alberca rectangular en el centro ${ }^{56}$, la cual fue cegada en el siglo XVI y sustituida por una fuente ${ }^{57}$ (Fig.7). En

${ }^{55}$ Concepción Rodríguez Moreno, "El Patio de las Doncellas del Alcázar de Sevilla en el Siglo XIV. Su análisis espacial a través de la infografía", Boletín de la Real Academia de Bellas Artes de Nuestra Señora de las Angustias de Granada, no 13, (2006), 34.

${ }^{56}$ Antonio Almagro Gorbea "Los jardines andalusíes y mudéjares del Real Alcázar de Sevilla", en Los jardines del Real Alcázar de Sevilla, 32.

${ }^{57}$ Antonio Almagro Gorbea, "Investigación y restauración en el Alcázar de Sevilla", Informes de la Construcción, vol. 64, nº Extra (2012), 99. 


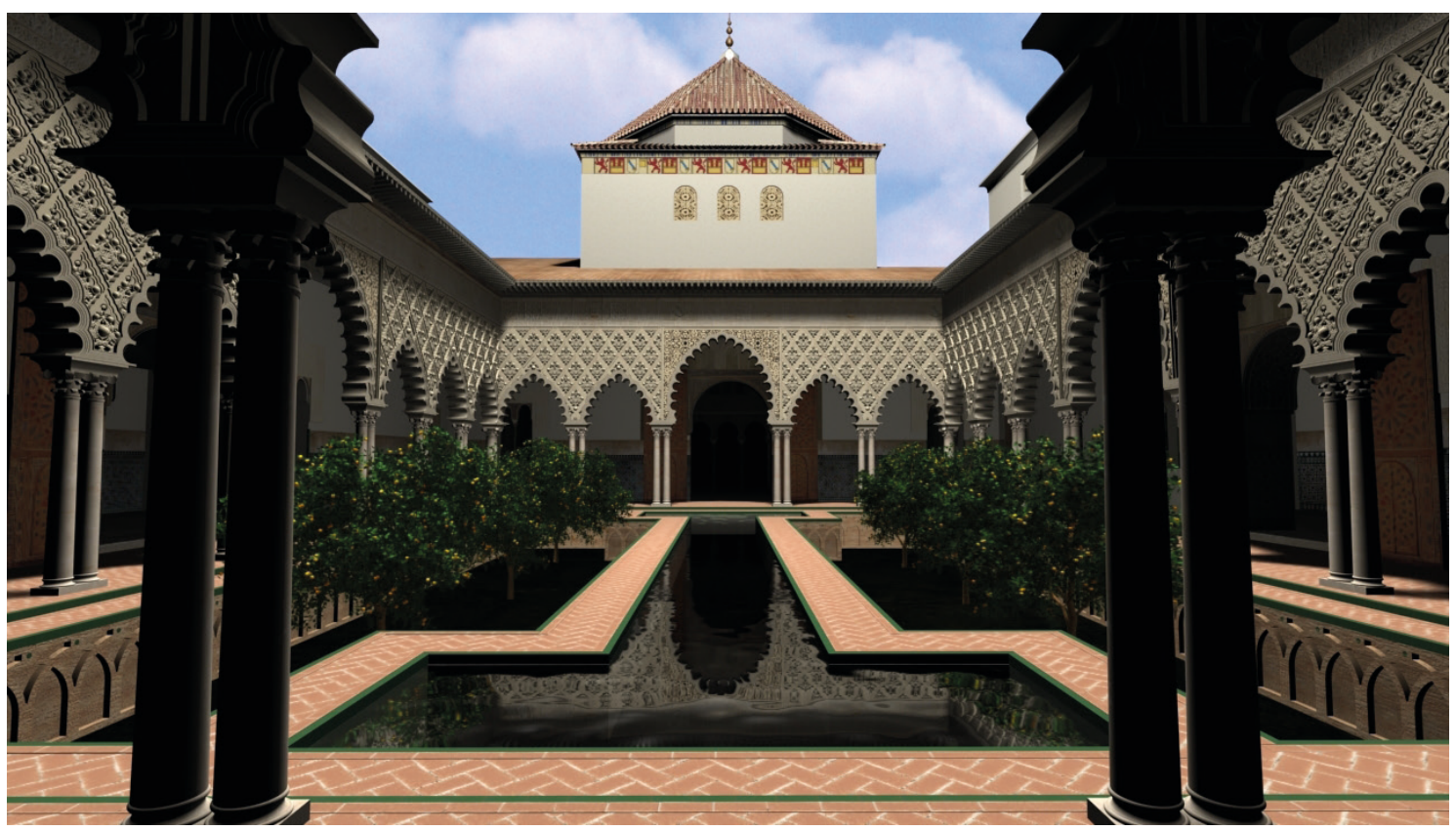

- Fig. 6. Antonio Almagro Gorbea (hipótesis), M. González y C. Rodríguez (imagen virtual). Patio del palacio de Pedro I según su proyecto original. Imagen: cortesía de A. Almagro Gorbea.

la carta del 23 de agosto de 1545 que Cárdenas escribió a Francisco de los Cobos encontramos el momento en que se propone esta nueva modificación, pues Cárdenas dice al respecto que "el quarto real tiene una alberca muy rica y daña el patio porque lo haze muy pequeño y lo humedece podriase hazer una muy buena pila en medio y ataparse el alberca $^{58 "}$. Sin embargo, esta intervención no debió ser instantánea ya que en diciembre de 1545 aún están arguyendo sobre el "patio que se ha de hazer de nuevo seria bien que se hiziese media vara de medir mas bajo que el cruzero porque el cuarto real quedara muy hondo ${ }^{59 \prime \prime}$.

\section{LUIS DE VEGA: MAESTRO DE CON- FIANZA}

Estas campañas de rehabilitación tuvieron un fuerte impacto en las estructuras interiores, especialmente, en los maderamientos de las cubiertas, como hemos podido comprobar hasta ahora, una cuestión que demuestra la importancia de las armaduras

\footnotetext{
${ }^{58}$ AGS, Estado, leg. 72, doc. 181.

${ }^{59}$ AGS, Estado, leg. 72, doc. 262
}

lignarias de tradición andalusí en la configuración del espacio áulico regio. Pero al mismo tiempo, es preciso considerar también la preocupación constante por el aspecto exterior del palacio en un proceso de regularización de su alzado del que Luis de Vega fue responsable, en gran medida, adelantándose a los deseos del emperador.

Vega construía rápido, con materiales económicos y adaptando las estructuras preexistentes para ganar en una nueva imagen de monumentalidad conseguida a través de la regularización aproximada de sus cuerpos de fábrica. El arquitecto supo edificar tanto cómodos interiores, como galerías en los patios a base de zapatas en madera o arcos de piedra que además dotasen a los interiores palaciegos de la necesaria salubridad y luz requerida por sus distinguidos habitantes; incluso aplicando materiales y formas foráneas como los mármoles provenientes de Italia.

Todas estas características son especialmente visibles en el actual Patio de las Doncellas. De hecho, cuando en 1546 Antonio de Cárdenas trasladó al príncipe Felipe en carta que, debido a la reestructuración de las es- 


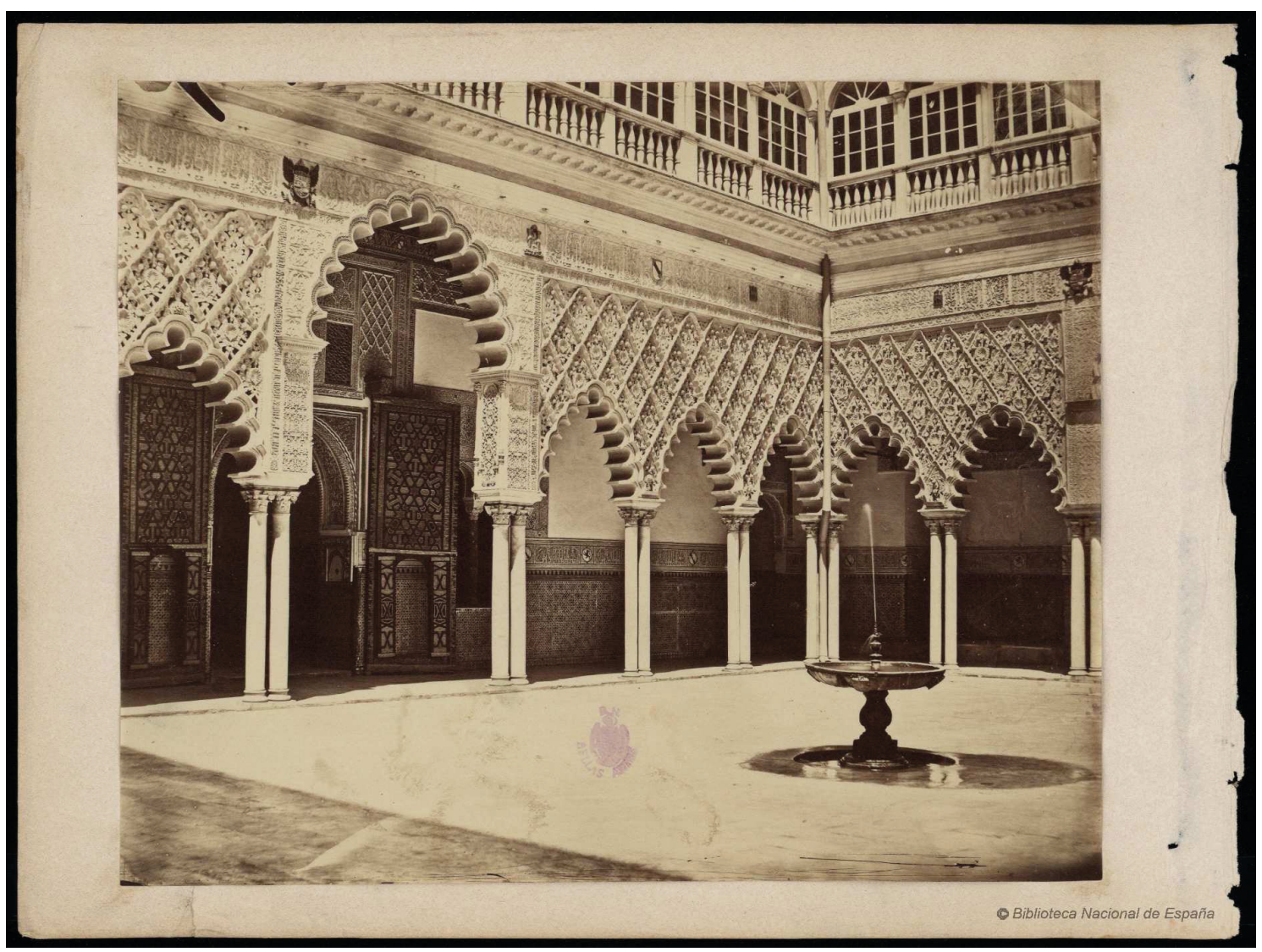

- Fig. 7. El Patio de las Doncellas antes de ser restaurado, ca.1880. Imagen: Biblioteca Nacional de España, 17/135/9.

tancias del emperador, Luis de Vega se vio obligado a retirar un tejado para facilitar la salida de aguas, Cárdenas justificó también el parecer del arquitecto sobre la conveniencia de replicar la estancia en la galería superior, a la espera de una decisión por parte del emperador. Es importante señalar que esta propuesta precedió a una nueva sugerencia del arquitecto, por la cual solicitaba la construcción de la arquería superior del patio principal que acompañó la realización de estos trabajos de acondicionamiento ${ }^{60}$.

Por tanto, la inclusión de las galerías superiores del Patio de las Doncellas reclama su plena iniciativa personal, pues hasta 1545 solo dos de los cuatro lados se encontraban cubiertos con techumbres de madera sobre pilares de ladrillo, como los presumió Ma-

${ }^{60}$ AGS, Estado, leg. 74, doc. 179, carta de Antonio de Cárdenas al príncipe Felipe a 6 de noviembre de 1546. rín Fidalgo ${ }^{61}$. De este modo, gracias a Cárdenas sabemos que Vega propuso cubrir las dos pandas que faltaban, cuestión a la que siempre se había opuesto el conde de Gelves: "porque dezia que escurecerían el cuarto real, [aunque] para mi [Antonio de Cárdenas] saneado estoy que no trae ningun inconveniente" ${ }^{\prime \prime 2}$.

${ }^{61}$ Marín Fidalgo, El Alcázar..., 135.

${ }^{62}$ AGS, Estado, leg. 74, docs. 179-180. Efectivamente, en el contrato que el maestre Adán Centurión firmó el 12 de diciembre de 1532 para la provisión de los mármoles genoveses del patio se especificó que Centurión, antes de confirmarlo, debía consultar el flete de las piezas con el alcaide, por lo que podemos presuponer que Gelves planteó problemas a esta empresa que terminaron por mantenerla en suspenso hasta 1545 . Esta hipótesis también explica por qué en 1540 se remodelan solo dos corredores altos en el patio y que en 1554 se trabaje sobre "los corredores que están haçiendo e cubriendo por mandado de Su Alteza", según un informe de los maestros mayores de albañilería y carpintería. Probablemente se remataron entre 1569 y 1570 junto a las ye- 
Asimismo, una de las razones de la preferencia del emperador por Luis de Vega es su versatilidad para asumir tareas distintas propias del maestro de obras tradicional. La cuestión de los materiales también fue competencia directa de Vega y así lo reiteraba continuamente el príncipe en su correspondencia con el teniente de alcaide en Sevilla. Además, el arquitecto buscó siempre soluciones prácticas a las dificultades logísticas. De hecho, cuando Cárdenas le propuso utilizar una piedra marmórea que se hallaba en una cantera a unas once leguas, probablemente las cercanas a Almadén de la Plata explotadas desde la Antigüedad, el arquitecto vio una oportunidad magnífica para aplicarla en la obra una vez acabadas las cajas de mármoles de Génova:

"Pareciole a Luis de Vega que se devia buscar cantera de una piedra marmolera que yo le mostre en esta casa. Yo la embie a buscar y le enbio la muestra dello para que lo muestra a Vuestra Señoria es muy estremada va polida por un cabo y por otro quebrada porque se ve en lo que a de quedar despues de acabados los marmoles los quales quiere para el Patio de la Monteria. Esta la cantera a XI leguas de aquí a las VI de venir por tierra y las $\mathrm{V}$ por agua a lo que tengo entendido costara poco menos que el doble que si se trujesen de Filabres o de Genova"63.

Vega también tuvo una habilidad especial en el reciclaje de los restos generados de los derribos y, el 26 de abril de 1546, el príncipe no dudó en ordenar que todo debía ser fiscalizado por el maestro mayor de obras reales, quien debía velar por el reaprovechamiento de elementos útiles, mientras que aquello que él considerase inútil "como puertas y ventanas y armaduras de viejo" debían darle la salida más ventajosa para obtener la máxima rentabilidad económica ${ }^{64}$. Finalmente, otra de las tareas que Luis de

serías que las decoran: Marín Fidalgo, El Alcázar..., 142, 153 y 155.

${ }^{63}$ AGS, Estado, leg. 74, docs. 179-180.

${ }^{64}$ AGS, Estado, leg. 74, doc. 21.
Vega hubo de asumir personalmente fue la provisión de madera para las obras del complejo áulico. La materia prima se extraía de la Sierra de Segura y se embarcaba a través del Guadalquivir hasta Sevilla. Sin embargo, el principal obstáculo era la inexistencia de personal dispuesto a asumir el peligroso trabajo de la corta, el transporte a través del escarpado terreno donde crecían los pinos y la conducción por el río, por tratarse de un trabajo demasiado peligroso por la exposición a sus crecidas ${ }^{65}$. En estas ocupaciones se encontraba el arquitecto inmerso todavía en febrero de 1547, fecha en la que se cierra esta fase a la que hemos dedicado nuestro artículo, cuando Vega se encontraba en Úbeda acompañando a Francisco de los Cobos en sus últimos meses de vida, mientras que atendía a este necesario asunto ${ }^{66}$.

\section{APÉNDICE DOCUMENTAL}

AGS, Estado, Legajo 74, doc. 190, Sevi1la, ¿31 de diciembre de 1545?

Memorial de Juan Fernandes maestro mayor de albañeria desta Casa

La yntencion del conde de Gelbes que es en gloria y de mi traza la primera fue aprovechar los hedificios viejos hechos por estar de buena obra y vista la voluntad de Su Magestad por una carta que el marques de Cortes me mostro por la qual dize que esta bien con mi traça porque le doy las pieças mayores que la otra traça con tanto que le de capilla y visto que no se tiene respeto a los hedificios viejos y que todos se derriban porque para bien labrar ansi conviene y para hazer el patio conforme a las pieças hize la traça presente sin tomar de la casa de la contratación mas de un corralete de siete varas en quadrado la qual se junta con los aposen-

${ }^{65}$ AGS, Estado, leg. 74, doc. 20, minuta de carta de Felipe II a Antonio de Cárdenas.

${ }^{66}$ AGS, Estado, leg. 74, doc. 20. No lo consiguió, pues el problema persistía un año después: AGS, Estado, leg. 66, doc. 137, Carta de Antonio de Cárdenas al secretario Ledesma. 
tos del quarto real como se vera por la traça alta/.

Va la capilla arrimada a la pared de la casa de la contratación tomando parte del sitio que se cerro de nuevo el anchura y longura por la traça se vera esta capilla es junto al aposento que a de ser de la emperatriz y junta con los oratorios para que desde el dicho aposento se pueda ver misa y Su Magestad desde la tribuna/.

La escalera va puesta entre el patio del crucero y el de la montería porque sirva a ambos patios y en lo alto della dexo un pasaje entre el escalera y la pared del cruzero o para que Su Magestad pase sin salir a corredor de su aposento a lo alto del quarto real y a donde posare la emperatriz. Este aposento de Su Magestad esta sobre el cruzero.

La galería que es aposento de damas se podrá hazer sobre la capilla y sobre la sala de la emperatriz y están junto al aposento de la emperatriz y tiene la vistas sobre el Canpo de Tablada y sobre el rio y no quita el sol al patio y si se les da aposento sobre la gran sala están lexos del aposento de la emperatriz/.

Debajo de la sala y de dos cámaras de la emperatriz se pueden hazer entresuelos que se manden por una escalera como por la traça se vera y debaxo destos y de la capilla se pueden hazer soterrenos de bóvedas a los quales se les podrá dar mucha luz y se mandaran por el patio de las cozinas y junto a todo el servicio.

En la memoria que dexo Luys de Vega dize que se haga el suelo del Patio de la Monteria al andar del cruzero si se haze el quarto real quedara muy baxo y el agua no podrá subir a fuente que sea alta y parece $q$ conviene que la tenga este patio.

Y si Vuestra Alteza fuere servido de mandar tomar mas parte de la Contrataçion se dara mayor patio a esta casa y la delantera quedara mejor y tomara mas de la plaça porque en esta traça no se toma mas de lo que esta dicho en mi primer capitulo.
Y por la traça de Gaspar de Vega se toma mas de la mitad de la Casa de la Contratación

Sobre todo Vuestra Alteza enbie a mandar lo que sea de hazer/.

Sevilla

Alcazares

El m. al. q enbia el teniente de allí o de Seviya de las obras

\section{BIBLIOGRAFÍA}

Almagro Gorbea, Antonio. “Investigación y restauración en el Alcázar de Sevilla”. Informes de la Construcción, vol. 64, nº Extra (2012), 95-108.

Almagro Gorbea, Antonio. "La planta alta del palacio de Pedro I en el Alcázar de Sevilla". Anuario del Departamento de Historia y Teoría del Arte, vol. 27, (2015), 69-115.

Almagro Gorbea, Antonio. “Los palacios de Pedro I. La arquitectura al servicio del poder". Anales de Historia del Arte, no 2 (2013), 25-49.

Chávez González, María Rosario. El Alcázar de Sevilla en el siglo XIX. Sevilla: Patronato del Real Alcázar de Sevilla, 2004.

Díaz González, Francisco Javier. La Real Junta de Obras y Bosques en la época de los Austrias. Madrid: Dyckinson, 2002.

Domínguez Casas, Rafael. Arte y etiqueta de los Reyes Católicos: artistas, residencias, jardines y bosques. Madrid: Alpuerto, 1993.

Fernández Aguilera, Sebastián. “Origen del Palacio de Pedro I en el Alcázar de Sevilla: el mirador hoy llamado de los Reyes Católicos". Archivo Español de Arte, vol. 88 , no 352 (2015), 331-348.

Fernández Rojas, Matilde. Las Reales Atarazanas de Sevilla. Sevilla: Diputación de Sevi1la, 2013.

Gil, Juan, El exilio portugués en Sevilla: De los Braganza a los Magallanes. Sevilla: Fundación Cajasol, 2009. 
Guerrero de Llanos, Eva. “El uso de la arquitectura como reafirmación política: la Maestría Mayor de Obras Reales en el siglo XVI y Luis de Vega". En Los Lugares del Arte: identidad y representación, vol. I, editado por Sofía Diéguez Patao, 133-158. Barcelona: Laertes, 2014.

Jiménez Martín, Alfonso. “Cronología documentada del contexto, antecedentes, construcción y uso del hospital de las Cinco Llagas, o de la Sangre, sede del Parlamento de Andalucía". En El edificio sede del Parlamento de Andalucía. El Hospital de las Cinco Llagas, 213-147. Sevilla: Parlamento de Andalucía, 2017.

Llaguno y Amírola, Eugenio. Noticias de los Arquitectos y Arquitectura de España desde su restauración. Madrid: Imprenta Real, 1892.

Marías Franco, Fernando. El largo siglo XVI. Madrid: Taurus, 1989.

Marín Fidalgo, Ana. El Alcázar de Sevilla bajo los Austrias, vol. I. Sevilla: Ediciones Guadalquivir, 1990.

Marín Fidalgo, Ana. Vermondo Resta. Sevilla: Diputación de Sevilla, 1988.

Marín Fidalgo, Ana y Plaza, Carlos, eds. Los jardines del Real Alcázar de Sevilla. Historia y Arquitectura desde el Medievo islámico al siglo XX. Sevilla: Patronato del Real Alcázar y Casa Consistorial, 2015.

Márquez Redondo, Ana Gloria. Los alcaides del Alcázar de Sevilla. Sevilla: Patronato del Real Alcázar, 2010.

Martínez Millán. José, coord. La corte de Carlos V: Vol. 2, Tomo 3: Los consejos y los consejeros de Carlos V. Madrid: Sociedad Estatal para la Conmemoración de los Centenarios de Felipe II y Carlos V, 2000.
Morales, Alfredo J. y Serrera, Juan Miguel. "Obras en los Reales Alcázares de Sevilla en tiempo de los Reyes Católicos". Laboratorio de Arte, no 12 (1999), 69-77.

Morales Martínez, Alfredo J. “Los Reyes Católicos y el Alcázar de Sevilla: De la restauración a la renovación". En Los Alcázares reales: vigencia de los modelos tradicionales en la arquitectura áulica cristiana, editado por Miguel Ángel Castillo Oreja. Madrid: Fundación BBVA, 2001, 129-144.

Pérez Ferrer, Juan Carlos y Fernández Aguilera, Sebastián. "La restauración del artesonado de la Sala del Techo de Carlos V del palacio mudéjar del Real Alcázar de Sevilla". Apuntes del Alcázar de Sevilla, nº 11 (2010), 38-61.

Pérez Gil, Javier. El Palacio Real de Valladolid: sede de la Corte de Felipe III (1601-1606). Valladolid: Universidad de Valladolid, 2006.

Pérez-Mallaína, Emilio. Las Atarazanas de Sevilla: Ocho siglos de historia del arsenal del Guadalquivir. Sevilla: Diputación de Sevi1la, 2019.

Ramiro Ramírez, Sergio. Patronazgo y usos artísticos en la corte de Carlos V: Francisco de los Cobos y Molina. Tesis Doctoral. Universidad Complutense de Madrid, 2018.

Redondo Cantera, María José. "La arquitectura de Carlos V y la intervención de Isabel de Portugal: palacios y fortalezas". En Carlos V y las artes: Promoción artística y familia imperial, 67-106, Valladolid: Junta de Castilla y León-Universidad de Valladolid, 2000.

Rodríguez Moreno, Concepción. “El Patio de las Doncellas del Alcázar de Sevilla en el Siglo XIV. Su análisis espacial a través de la infografía". Boletín de la Real Academia de Bellas Artes de Nuestra Señora de las Angustias de Granada, no 13, (2006), 31-56. 